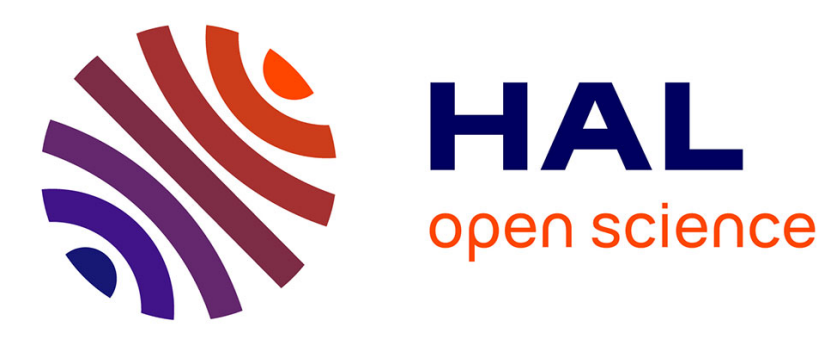

\title{
Polyethersulfone hollow fiber modified with poly(styrenesulfonate) and Pd nanoparticles for catalytic reaction
}

Clélia Emin, Yingying Gu, Jean-Christophe Remigy, Jean-Francois Lahitte

\section{- To cite this version:}

Clélia Emin, Yingying Gu, Jean-Christophe Remigy, Jean-Francois Lahitte. Polyethersulfone hollow fiber modified with poly(styrenesulfonate) and $\mathrm{Pd}$ nanoparticles for catalytic reaction. The European Physical Journal. Special Topics, 2015, vol. 224 (n 9), pp. 1843-1848. 10.1140/epjst/e2015-02503-y . hal-01287684

\section{HAL Id: hal-01287684 \\ https://hal.science/hal-01287684}

Submitted on 14 Mar 2016

HAL is a multi-disciplinary open access archive for the deposit and dissemination of scientific research documents, whether they are published or not. The documents may come from teaching and research institutions in France or abroad, or from public or private research centers.
L'archive ouverte pluridisciplinaire HAL, est destinée au dépôt et à la diffusion de documents scientifiques de niveau recherche, publiés ou non, émanant des établissements d'enseignement et de recherche français ou étrangers, des laboratoires publics ou privés. 


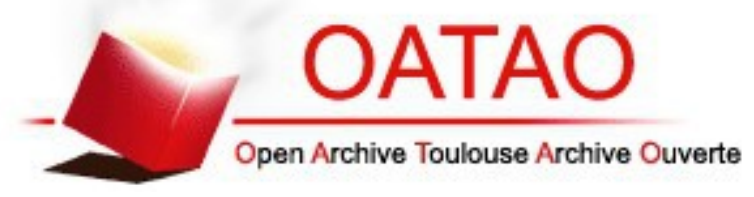

\section{Open Archive TOULOUSE Archive Ouverte (OATAO)}

OATAO is an open access repository that collects the work of Toulouse researchers and makes it freely available over the web where possible.

This is an author-deposited version published in : http://oatao.univ-toulouse.fr/ Eprints ID : 15579

To link to this article : DOI:10.1140/epjst/e2015-02503-y URL : http://dx.doi.org/10.1140/epjst/e2015-02503-y

To cite this version : Emin, Clélia and Gu, Yingying and Remigy, Jean-Christophe and Lahitte, Jean-Francois Polyethersulfone hollow fiber modified with poly(styrenesulfonate) and Pd nanoparticles for catalytic reaction. (2015) The European Physical Journal Special Topics, vol. 224 ( $n^{\circ}$ 9). pp. 1843-1848. ISSN 1951-6355

Any correspondence concerning this service should be sent to the repository administrator: staff-oatao@listes-diff.inp-toulouse.fr 


\title{
Polyethersulfone hollow fiber modified with poly(styrenesulfonate) and Pd nanoparticles for catalytic reaction
}

\author{
C. $\operatorname{Emin}^{1,2}$, Y. Gu ${ }^{1,2}$, J.-C. Remigy ${ }^{1,2}$, and J.-F. Lahitte ${ }^{1,2, a}$ \\ 1 Université de Toulouse; INPT, UPS; Laboratoire de Génie Chimique; 118 Route de \\ Narbonne F-31062 Toulouse, France \\ 2 CNRS; Laboratoire de Génie Chimique; F-31030 Toulouse, France
}

\begin{abstract}
The aim of this work is the synthesis of polymer-stabilized $\mathrm{Pd}$ nanoparticles (PdNP) inside a functionalized polymeric porous membrane in order to develop hybrid catalytic membrane reactors and to test them in model metal-catalyzed organic reactions. For this goal, a polymeric membrane support (Polyethersulfone hollow fibershaped) was firstly functionalized with an ionogenic polymer (i.e. poly(styrenesulfonate) capable to retain PdNP precursors using an UV photo-grafting method. PdNP were then generated inside the polymeric matrix by chemical reduction of precursor salts (intermatrix synthesis). The catalytic performance of the PdNP catalytic membranes was evaluated using reduction of nitrophenol by sodium borohydride $\left(\mathrm{NaBH}_{4}\right)$ in water.
\end{abstract}

\section{Introduction}

Nowadays researches have revealed a great interest for nano-scale materials in catalysis field. Many studies have shown the high efficiency of metal nanoparticles (MNP) when they are dispersed in a suitable media [1,2]. However, without stabilizing agents such as polymers or surfactant [3], nanoparticles demonstrate a high trend to agglomerate in solution and to form aggregates resulting in a loss of reactivity. Owing to such considerations, functionalized polymeric membrane can be a suitable stabilizer for MNP and a crucial barrier in catalysis for easy separation of the product from the reaction mixture, which is favorable in several cases of consecutive reactions [4]. In flow-through process configuration, catalytic reactive membrane reactor offers the possibility to make the reaction and the separation in one step. Various techniques such as Layer-by-Layer [5] or aqueous phase polymerization [6] have been used to functionalize membranes in order to obtain a stabilizing layer at the membrane surface. In this work, we describe a versatile route to modify surface hollow fiber membranes by UV photo-grafting method in order to evaluate the impact of grafted chains of

a e-mail: lahitte@chimie.ups-tlse.fr 
poly(styrenesulfonate) (PSS) on the amount of loaded palladium and on the reactivity of the catalytic nanoparticles. Catalytic membrane reactors are often made in ceramic membrane materials for high temperature and gaseous reactions [7]. The use of polymeric membranes in mild reaction conditions (room temperature, reaction in water) offers new opportunity for processes intensification in terms of energy and product cost.

\section{Methods}

Microfiltration polyethersulfone hollow fibers (PES) were chosen as the support material (MicroPES ${ }^{\circledR}$ purchased from Membrana, Wuppertal, Germany). A monomer solution made of $15 \mathrm{wt} \%$ of sodium styrenesulfonate(NaSS), $5 \mathrm{wt} \%$ of N, N-methylenebis-acrylamide (crosslinker) and $0.1 \mathrm{wt} \%$ of hydroxybenzophenone (photoinitiator) was used. The compounds were used as received from Aldrich. PSS was grafted onto the hollow fiber surface through a continuous process using a photo-grafting setup that is equipped with two powerful UV polychromatic lamps as described in a previous article [8]. Energy received by the membrane surface was modulated by the irradiation time ( $\sim$ few seconds). Different grafted membranes were then obtained with $-\mathrm{SO}_{3}^{-} \mathrm{Na}^{+}$functional groups. Membranes were finally washed with ultrapure water until no carbon was detected in washing solution (analyzed by Total Organic Carbon Shimadzu apparatus).

The amount of grafted polymer chains was determined using Blue toluidine $\mathrm{O}$ (BTO) colorimetric method [9] The synthesis of palladium nanoparticles inside the polymer was achieved by the reduction of palladium salt $\left(\mathrm{Pd}\left(\mathrm{NH}_{3}\right)_{4} \mathrm{Cl}_{2}\right)$ by an aqueous solution of sodium borohydride, described as the "Inter-matrix synthesis" [10]. The amount of palladium was determined by inductively coupled plasma optical emission spectrometry (ICP-OES Ultima 2, Horoba Jobin Yvon). Images of grafted membranes were obtained using a scanning electron microscope (SEM) coupled with energy-dispersive X-ray spectroscopy (EDX) giving information on graft thickness and the localization of MNP. The reduction of p-nitrophenol in p-aminophenol was performed with the different hollow fibers in convection mode (i.e. filtration through the membrane) in order to characterize the performance of the new material. The concentration of p-nitrophenol was monitored by UV-visible spectrometry $(\lambda=400 \mathrm{~nm}$, UVlight, XTD5) versus time in order to follow the conversion. The permeability was determined by the slope of the plot of flux $\left(\mathrm{g} \mathrm{min}^{-1} \mathrm{~cm}^{-2}\right.$ or $\left.\mathrm{L} \mathrm{min}^{-1} \mathrm{~m}^{-2}\right)$ as a function of transmembrane pressure (bar) using method described in a previous article [4].

\section{Results and discussions}

\subsection{Effect of UV filter}

The UV radiation spectra received by the polymeric membrane surface can be changed using specific filters placed between the lamp and the membrane. We have used a quartz filter (transparent for UV radiation from $200 \mathrm{~nm}$ ) and a Pyrex filter (transparent from $290 \mathrm{~nm}$ ). We have compared the amount of grafted polymer for the two UV filters. Figure 1 presents the evolution of the grafting PSS amount as a function of the irradiation time. We can observe that, for a range of irradiation time between $2 \mathrm{~s}$ and $3.75 \mathrm{~s}$, the mass of grafted PSS was higher when using quartz filter than Pyrex filter. Then upon $7.5 \mathrm{~s}$ the mass of grafted PSS was rather equal for both filters. At this value, the totality of monomer present in the solution film layer covering the fiber was consumed during the polymerization. Due to the photo reactivity of the PES [11], 


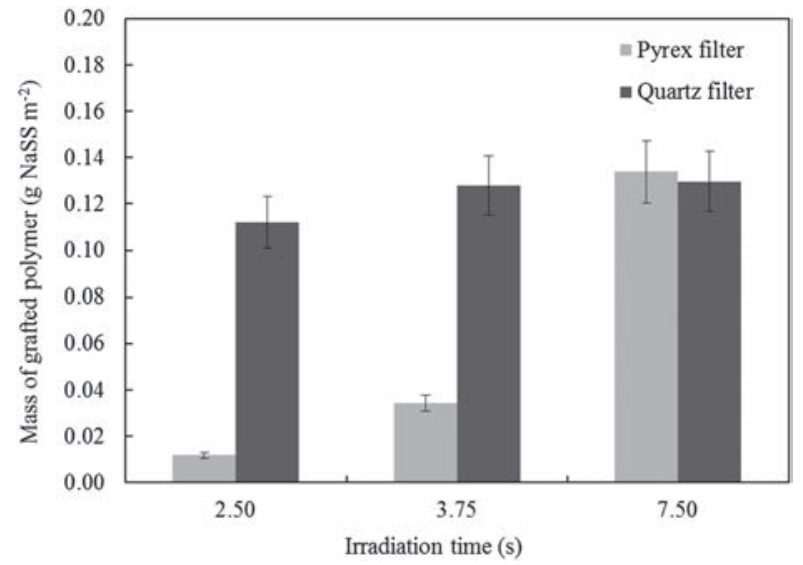

Fig. 1. Mass of grafted PSS on the membrane surface (MicroPES ${ }^{\circledR}$ ) for Pyrex and quartz filter as a function of the irradiation time (based on 3 samples per run).
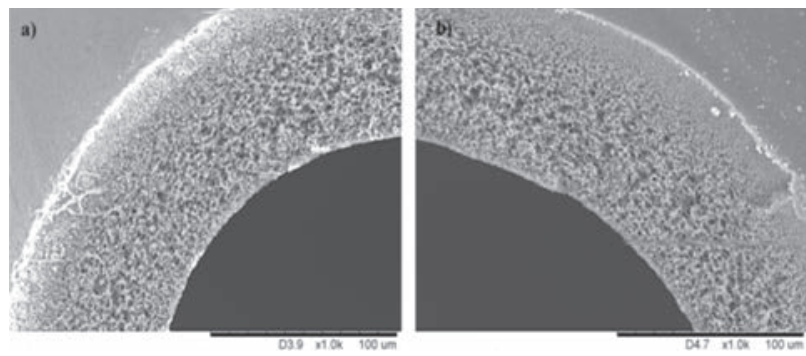

Fig. 2. MEB images of stained MicroPES ${ }^{\circledR}$ hollow fiber cross section a) PES-PSS6 grafted membrane b) pristine membrane.

the quartz filter is more efficient than Pyrex filter, the large UV wavelength range favoring a high initiation rate of radical species at the membrane surface.

\subsection{Structural characterization of the modified layer}

Direct visualization of the membrane surface does not allow distinguishing the grafted layer from the membrane support due to a too close chemical composition of the grafted layer and the membrane. An ionic exchange of $\mathrm{Na}^{+}$by $\mathrm{Ag}^{+}$(using a $\mathrm{AgNO}_{3}$ solution) allowed to observe a contrast difference in MEB imaging between the support PES membrane and the grafted PSS bearing complex $-\mathrm{SO}_{3}^{-}$group (Fig. 2). We can clearly see the grafted layer stained by $\mathrm{Ag}^{+}$ion as a bright zone appearing in the membrane surface zone in MEB images.

In our experimental conditions, the grafting polymerization of NaSS led to an interpenetrated network while the grafting of acrylic acid (which is more reactive) studied in previous work, led to a pseudo-dense polymer layer on the membrane surface $[11,14]$.

The depth of this network, revealed by $\mathrm{Ag}^{+}$marking, was estimated in MEB picture between 5 and $20 \mu \mathrm{m}$ (Table 1).

The amount of grafted polymer versus the UV energy received by the hollow fiber membrane is presented on Fig. 3. We observe three different zones. At low energy (lower than $0-10 \mathrm{KJ} . \mathrm{m}^{-2}$ ), the UV energy is consumed by the inhibitor present in the 
Table 1. Depth of the interpenetrated network and mass of grafted PSS (based on 3 samples per run).

\begin{tabular}{lcc}
\hline Sample & $\begin{array}{c}\text { Mass of grafted } \\
\text { polymer } \\
\left(\text { g NaSS m }^{-2}\right)\end{array}$ & $\begin{array}{c}\text { Depth of the } \\
\text { network }(\mu \mathbf{m})\end{array}$ \\
\hline PES-PSS1 & $0.01 \pm 0.01$ & $5 \pm 3$ \\
PES-PSS2 & $0.03 \pm 0.01$ & $9 \pm 3$ \\
PES-PSS3 & $0.13 \pm 0.01$ & $16 \pm 3$ \\
PES-PSS5 & $0.128 \pm 0.001$ & $20 \pm 3$ \\
PES-PSS6 & $0.130 \pm 0.001$ & $19 \pm 3$ \\
\hline
\end{tabular}

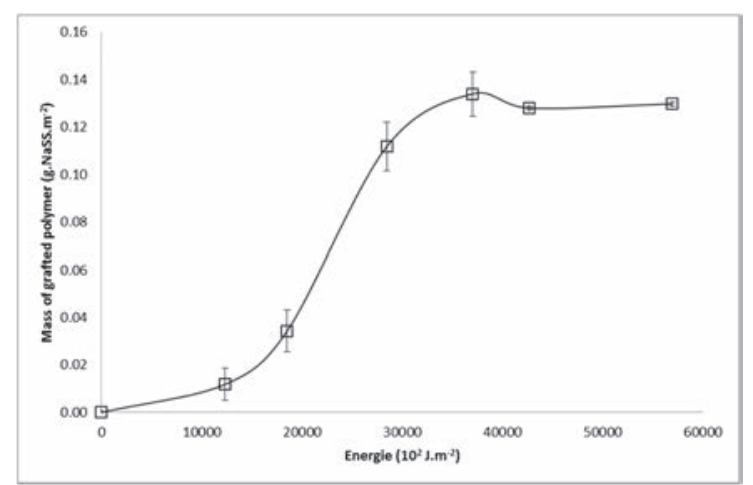

Fig. 3. Mass of grafted PSS vs received UV energy for MicroPES ${ }^{\circledR}$ PES-PSS1 à PES-PSS6 (based on 3 samples per run).

monomer solution or by the oxygen dissolved in the solution [12]. In this condition, the amount of grafted polymer is very low due to the inhibition of the polymerization. After consumption of $\mathrm{O}_{2}$ and of the inhibitor (energy: 10-37 KJ.m ${ }^{-2}$ ), monomer reacts with initiating radicals leading to an increase of the polymerization rate [13]. For energy higher than $40 \mathrm{KJ} . \mathrm{m}^{-2}$, no more change is observed; the total consumption of the monomer is reached. So, the amount of grafted polymer can be easily changed by changing the energy received by the membrane. The knowledge of the minimal energy for total consumption of monomer permits to optimize the process, saving time, products and energy.

\subsection{Effect of NP presence on pure water permeability}

We observed that the presence of $\mathrm{Pd}$ nanoparticles decreased the water permeability of the membrane from 20 to $100 \%$ (Fig. 4). Smuleac had observed this decrease of permeability in the case of PVDF membrane charged with iron nanoparticles. A blockage of pores may occur by aggregates of NP [15].

\subsection{Catalytic test of Pd loaded membrane}

4-nitrophenol (4-NP) reduction in 4-aminophenol (4-AP) in presence of $\mathrm{NaBH}_{4}$ in water (Eq. (1)) is a model reaction of degradation of organic molecule [16].

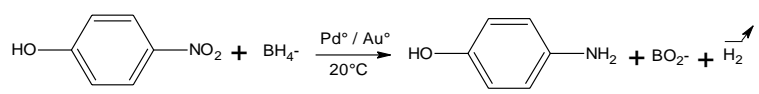




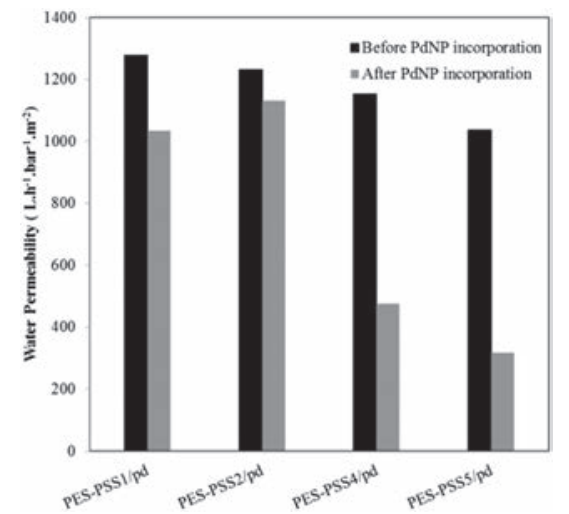

Fig. 4. Effect of PdNP loading in water permeability of membrane.

Table 2. 4-NP conversion obtain $[4-\mathrm{NP}]=0.72 \mathrm{mmol} \mathrm{L}^{-1} ;\left[\mathrm{NaBH}_{4}\right]=72.00 \mathrm{mmol} \mathrm{L}^{-1}$, $\mathrm{S}_{\text {fibre }}=8.6 \mathrm{~cm}^{2}$.

\begin{tabular}{|c|c|c|c|c|}
\hline Sample & $\begin{array}{c}\text { mass of Pd } \\
\left(\mathrm{mg} \mathrm{cm}^{-2}\right)\end{array}$ & $\begin{array}{l}\text { Flux } \pm \mathbf{1 0 \%} \\
\left(\mathbf{L ~ h}^{-1} \mathbf{m}^{-2}\right)\end{array}$ & $\begin{array}{l}\text { Conversion } \\
\text { 4-NP }(\%)\end{array}$ & $\begin{array}{l}\text { 4-AP Molar flux } \\
\left(\mathrm{mmol} \cdot \mathrm{h}^{-1} \cdot \mathrm{m}^{-2}\right)\end{array}$ \\
\hline PES-PSS5/Pd & 0.010 & 55 & 100 & 39.6 \\
\hline PES-PSS1/Pd & 0.008 & 80 & 97 & 55.8 \\
\hline PES-PSS2/Pd & 0.008 & 122 & 63 & 55.3 \\
\hline
\end{tabular}

This reaction can be easily monitored by UV spectroscopy since 4-NP and 4-AP absorbance peaks are quite different. Results exposed in Table 2 indicate that a total conversion can be achieved. We observed that increasing the flux leads to a decrease of the conversion while the production flux of 4-AP increases, corresponding to a contact time with the catalytic layer between 0.2 to $1.3 \mathrm{~s}$. Thus there is an optimum in term of productivity and efficiency of the process as a function of the $\mathrm{Pd}$ amount and operating flux.

4-AP molar fluxes ([4-AP]Flux) obtained with our catalytic membranes are closed to those obtained in batch conditions where catalytic membrane is mixed with the solution [10]. The interest of the catalytic membrane process is to obtain in a continuous mode a pure product since the beginning of the production without waiting for a total conversion of reactants that can take a long time in batch process.

\section{Conclusion}

Efficient catalytic hollow fibers were developed based on graft polymerization of sodium styrene sulfonate induced by UV irradiation. A controllable method was developed by varying the operating parameters. Catalytic membrane was obtained and can be used in flow through membrane contactor. The performance of the catalytic hollow fibers was confirmed by the reduction of p-nitrophenol with a conversion rate close to $100 \%$ in few seconds of reaction time.

The authors would like to gratefully acknowledge the "Ministère Français de l'Enseignement Supérieur et de la Recherche" for funding scholarships.

\section{References}

1. J.E. Mondloch, E. Bayram, R.G. Finke, J. Mol. Catal. A-Chem. 355, 1 (2012)

2. D. Astruc, Nanoparticles Catal. 1 (2008) 
3. D. Astruc, F. Lu, J.R. Aranzaes, Angew. Chem. Int. Ed 44, 7852 (2005)

4. S. Miachon, J.A. Dalmon, Top. Catal. 29, 59 (2004)

5. L. Ouyang., D.M. Dotzauer, S.R Hogg, J. Macanás, J.F. Lahitte, M.L. Bruening, Catal. Today 156, 100 (2010)

6. V. Smuleac, R. Varma, S. Sikdar, D. Bhattacharyya, J. Membr. Sci. 379, 131 (2011)

7. A. Basile, F. Gallucci, Membranes for Membranes Reactors, Preparation, Optimization and Selection, Wiley (2011)

8. A. Akbari, S. Desclaux, J.C. Rouch, J.C. Remigy, J. Membr. Sci. 297, 243 (2007)

9. A. Michiardi, G. Hélary, P.C. Nguyen, L.J. Gamble, F. Anagnostou, D.G. Castner, V. Migonney, Acta Biomater. 667 (2010)

10. P. Ruiz, M. Muñoz, J. Macanás, C. Turta, D. Prodius, D.N. Muraviev, Dalton Trans. 39, 1751 (2010)

11. M. Ulbricht, M. Riedel, U. Marx, J. Membr. Sci. 120, 239 (1996)

12. C. Emin, J-.C. Remigy, J-.F. Lahitte, J. Membr. Sci. 455, 55 (2014)

13. R. Li, F.J. Schork, Ind. Eng. Chem. Res. 45, 3001 (2006)

14. C. Decker, A.D Jenkin, Macromolecules 18, 1241 (1985)

15. C. Emin, Élaboration d'un réacteur membranaire catalytique par fonctionnalisation de surface de membranes polymères et intégration de nanoparticles métalliques : application à la chimie douce, PhD dissertation, Université de Toulouse (2013)

16. V. Smuleac, R. Varma, S. Sikdar, D. Bhattacharyya, J. Membr. Sci. 379, 131 (2011)

17. K.B. Narayanan, N. Sakthivel, J. Hazard. Mater. 189, 519(2011) 